\title{
LETTER
}

\section{Which diet is best for diabetes?}

\author{
K. Esposito • M. Maiorino • D. Giugliano
}

Received: 21 January 2009 / Accepted: 22 January 2009/Published online: 17 February 2009

(C) Springer-Verlag 2009

Keywords Diabetes $\cdot$ Diet $\cdot$ Mediterranean diet

To the Editor: We read with pleasure the editorial by Sawyer and Gale [1] on diet and diabetes. Although for the diabetic patient the health benefits of dieting (improved metabolic control, weight loss, reduced risk of vascular disease) are not as great as that currently expected from any antihyperglycaemic drug (improved glucose control), we agree that the optimal diet should have pleiotropic effects to reduce the burden of diabetes. Considering the poor quality of life of some diabetic patients, delaying the development of the disease is crucial, and much more attention should be paid to lifestyle. Needless to say, there is little emphasis on lifestyle, including diet, in current recommendations for patients with diabetes.

A Mediterranean diet substantially reduced the risk of type 2 diabetes in 13,380 healthy Spanish university graduates [2], and in 8,291 Italian patients who had suffered a myocardial infarction in the last 3 months [3]. Moreover, a Mediterranean diet may help reduce the prevalence of metabolic syndrome [4]. However, interventional evidence for the benefits of a Mediterranean diet in the routine care of type 2 diabetic patients is scanty. Among 36 patients with diabetes evaluated in a 2-year study of three different dietary approaches to weight loss, changes in fasting glucose and insulin levels were more favourable for those assigned to a Mediterranean diet than those assigned to a

\footnotetext{
K. Esposito $\cdot$ M. Maiorino $\cdot$ D. Giugliano $(\bowtie)$

Department of Geriatrics and Metabolic Diseases, Second University of Naples,

Piazza L. Miraglia 2,

80138 Naples, Italy

e-mail: dario.giugliano@unina2.it
}

low-fat diet [5]. A Mediterranean diet seems to have pleiotropic effects that may improve the cardiovascular outlook for the diabetic patient, including reduced oxidative stress and subclinical inflammation, and amelioration of endothelial dysfunction and insulin sensitivity [6].

But which style of Mediterranean diet is best for diabetes? The general principles of the Mediterranean diet are based on increased consumption of whole grains, legumes, vegetables, fish, fruits, olive oil and nuts, but the proportions of macronutrients may vary. The results of the Nurses' Health Study [7] showed that low-carbohydrate diets are not associated with an increased risk of type 2 diabetes in women, and may in fact be protective if associated with an increased consumption of vegetable sources of fat and protein. However, the apparently Solomonic statement from the American Diabetes Association in support of the wide range of energy obtained from carbohydrate (45-65\%) assumes a different perspective. Mutatis mutandis, the concept of a low-carbohydrate diet adapted to a Mediterranean diet is intriguing. Supporting evidence comes from recent results showing that overweight women with the metabolic syndrome consuming a low-carbohydrate Mediterranean diet lost more weight than those consuming an isoenergetic high-carbohydrate Mediterranean diet, and had a better lipid and inflammatory profile [8]. Restriction of carbohydrate within a Mediterranean diet may be advantageous for people with type 2 diabetes.

An ideal diet should include the many components thought to be beneficial for cardiometabolic risk, including all specific types of fat, carbohydrate and protein. Although a description of such an all-inclusive diet is still lacking, it seems that a low-carbohydrate Mediterranean diet has most of the desired attributes, including a lower content of refined carbohydrate, a high fibre content, a moderate fat 
content (mostly monounsaturated), and a moderate to high content of vegetables and protein. A Mediterranean diet is perhaps best described by the word 'frugal' (from the Latin 'fruges', used in reference to products of the earth): the adjectives 'spare' and 'sensible' used by Sawyer and Gale [1] to define the best diet for diabetes could also apply to a Mediterranean diet.

\section{References}

1. Sawyer L, Gale EAM (2009) Diet, delusion and diabetes. Diabetologia 52:1-7

2. Martínez-Gonzáles MA, de la Fuente-Arrillaga C, Nunez-Cordoba JM et al (2008) Adherence to Mediterranean diet and risk of developing diabetes: a prospective cohort study. BMJ 336:13481351

3. Mozaffarian D, Marfisi R, Levantesi G et al (2007) Incidence of new-onset diabetes and impaired fasting glucose in patients with recent myocardial infarction and the effect of clinical and lifestyle risk factors. Lancet 370:667-675

4. Giugliano D, Ceriello A, Esposito K (2008) Are there specific treatments for the metabolic syndrome? Am J Clin Nutr 87:8-11

5. Shai I, Schwarzfuchs D, Hnekin Y et al (2008) Weight loss with a low-carbohydrate, Mediterranean, or low-fat diet. N Engl J Med 359:229-241

6. Esposito K, Giugliano D (2006) Diet and inflammation: a link to metabolic and cardiovascular diseases. Eur Heart J 27:15-20

7. Halton TL, Liu S, Hu FB (2008) Low-carbohydrate-diet and risk of type 2 diabetes in women. Am J Clin Nutr 87:339-346

8. Esposito K, Ciotola M, Giugliano D (2007) Low-carbohydrate diet and coronary heart disease in women. New Engl J Med 356:750752 